\title{
Emergent Professional Learning Communities in Higher Education: Integrating Faculty Development, Educational Innovation, and Organizational Change at a Canadian College
}

\author{
Julie A. Mooney \\ University of Saskatchewan
}

\begin{abstract}
Centres for teaching and learning at postsecondary educational institutions in Canada seek to serve the professional development needs of faculty members throughout the college or university. Recognizing the limits of conventional frameworks for faculty development, such as one-time workshops, pedagogical conferences, and lunchtime discussion sessions, this interpretive inquiry explores learning communities as an additional framework for serving faculty development and cross-institutional professional development needs. The study asks: what does it mean for faculty, educational developers, support staff, and administrators to participate in a learning community at a college in Canada? Data collected through individual inquiry conversations (semi-structured interviews) and research memos were used to develop narrative descriptions representing the participants' respective experiences of a learning community in a large, urban college context in Canada. These narrative descriptions offer portraits of the meaning that learning community members made of their own experience, revealing that the learning communities served not only as sites for professional development, but also formed microcultures within the institution, which, over time, influenced educational (academic) and organizational (administrative) change, both in policy and in practice.
\end{abstract}

\section{Introduction}

This article presents and discusses the results of an interpretive inquiry into emergent professional learning communities (PLCs) at a large, urban, Canadian college, and the influences they had at that institution on faculty development, educational innovation, and organizational change. For the purpose of this study, the term learning community refers to a group of people, affiliated with a postsecondary educational institution, as employees or students, who share a common interest and undertake to inquire about it together (Cox, 2004; Goodsell Love, 2012; Macpherson, 2007; Senge, 
2006; Wenger, 1998;). The use of learning communities in education is not new, but it is not widely applied to faculty development programming, which tends towards brief, one-time sessions that aim to intervene on a particular teaching or curricular skill or strategy (Beach, Sorcinelli, Austin, \& Rivard, 2016).

\section{Significance of the Study}

Faculty development units, like most academic services within higher education, are increasingly under pressure from senior leadership to show evidence of the effectiveness and impact of their programming (Beach, Sorcinelli, Austin, \& Rivard, 2016; Condon, Iverson, Manduca, Rutz, \& Willett, 2016; Schroeder, 2011). The effectiveness and impact of faculty development services are often measured in quantitative terms. In the Canadian higher education sector, faculty learning communities (FLCs), which meet regularly for a full academic year, ranked low on a scale of signature approaches to faculty development (Beach et al., 2016). Only 17\% of Canadian respondents ranked FLCs in their top three approaches, while less time-consuming approaches, such as hands-on workshops and individual consultations rated high (Beach et al., 2016). The current study sought to better understand the quality of professional learning afforded by learning communities, and to gain greater insight into this form of faculty development. This interpretive inquiry revealed understandings of faculty development from wider, institutional, and integrative perspectives.

\section{Problem Statement and Research Question}

Centres for teaching and learning in postsecondary educational institutions in Canada seek to serve the professional development needs of faculty members throughout the college or university. Recognizing the limitations of conventional frameworks for faculty development, such as onetime workshops, pedagogical conferences, and lunchtime discussion sessions, this interpretive inquiry explored learning communities (LCs), as an additional and integrative framework for serving faculty development and cross-institutional professional development needs. The study asked: What does it mean for faculty, educational developers, support staff, and administrators to participate in a learning community at a college in Canada?

\section{Inspiration for the Study}

In 2009, while working as an educational developer in a centre for teaching and learning, colleagues and I had the opportunity to hear George Kuh speak about high impact educational practices (Kuh, 2009). Shortly thereafter, we started thinking about and discussing how learning communities - one of Kuh's (2009) high impact practices for students - could apply to faculty professional learning. A disciplinary background in Peace Studies had provided me with theoretical and practical understandings about community-building. As I designed and developed various faculty development programs and sessions, I made efforts to cultivate community as a 
core component of these programs (Mooney, 2014). Simultaneously, faculty members at the same institution were engaged in similar community-building efforts. Over the course of a few years, several such communities formed at the college, both through formal faculty development programming and as emergent learning communities.

Initially, I thought about these emergent communities as faculty learning communities, because they had been initiated by faculty members. However, as I pursued the research discussed in this article, these communities revealed themselves to me as inclusive of colleagues from various professional roles, and in some cases, inclusive of students as well. As my study progressed through semi-structured interviews with participants from these communities, my thinking about these groupings of colleagues changed. They were not simply sites of faculty development in the conventional professional development programming sense of the phrase; they were emergent professional learning communities (PLCs) that had been built from the ground up by individuals who sought out colleagues with whom to learn collaboratively about their shared curiosity or conundrum.

\section{Conceptual Framework}

While the concept of learning as a community first appeared in colleges and universities in the 1920s, learning communities started to prove effective and to take root in higher education in the 1990s (Brownell \& Swaner, 2009; Meiklejohn, 1932). Much of the literature on learning communities in higher education contexts has focused on student or student-faculty learning communities (Kuh, 2009; Brownell \& Swaner, 2009; Price, 2005; Garrison \& Anderson, 2003; Lenning \& Ebbers, 1999; Gabelnick et al., 1990). This study took a broader look at the whole institution, through the lens of Senge's (2006) learning organization concept. While not entirely excluding student participation, this study focused primarily on the participation of faculty, educational developers, staff, and administrators in learning communities. Lenning and Ebbers (1999) highlight that applications of the learning community model have grown beyond the classroom context:

Learning communities can be philosophically related to Deweyan principles - that education is most successful as a social process and is deeply rooted in our understanding of community and democracy. As we understand learning communities today, they evolved out of cooperative and collaborative learning movements that emphasized social interaction and active learning. Learning communities were almost always discussed in relation to the classroom. But what was once a pedagogical tool is now being used to transform all sorts of campus features, including classrooms, retention programs, distance learning, residential environments, and many other structures. (p. 11)

Professors at postsecondary institutions in Canada are selected to teach based on their subject matter expertise; seldom are they required to have prior credentials in the scholarship of teaching and learning (Heinrich, 2014; Mooney, 2015). Their professional development as educators is therefore of instrumental importance to the quality of learning opportunities they offer 
students (Mooney, 2015). In Canada, postsecondary centres for teaching and learning have been established by senior administrations with the explicit mandate to serve faculty development needs (Mooney, 2015). Teaching and learning service units often experience low participation rates in their faculty development programming (Heinrich, 2014; Mooney, 2015), which typically include such offerings as new faculty orientation, course design and assessment workshops, pedagogical discussion series, and one-one-one consultations. Despite the quality, variety, and number of services offered by educational developers, for some centres for teaching and learning, outreach to faculty to support their development as teachers remains challenging (Mooney, 2015).

Faculty development programs that are designed as one-time sessions do not necessarily create conditions for deep professional learning. As an educational developer who has grappled with these challenges, I ask myself: (a) what could teaching and learning services in postsecondary education do to create conditions for sustained learning over time that is rooted in professional practice? and (b) are the teachers who do not participate in teaching and learning development opportunities finding other outlets for ongoing professional development as educators? These questions are central to my conceptual framework, a tentative theory for the phenomenon under investigation (Maxwell, 2005).

According to a pilot study conducted in Canada in 2014-2015, some faculty members appear to be going elsewhere to find and create their own opportunities for ongoing professional learning, independent of opportunities offered by centres for teaching and learning (Mooney, 2015). Some are connecting with colleagues from across or beyond their institution in what appear to be learning communities focused on a common need, a special project, or a shared area of interest (Mooney, 2015). These groups of collaborative, self-directed, self-starters are the types of learning communities at the centre of the study discussed in this article.

In this inquiry, I investigated the phenomena of five learning communities within a Canadian college that, at the time of data collection, were generally viewed, by administrators, faculty, educational developers, and support staff at the college, as successful initiatives because of either their longevity, their number of active or affiliated members, the impact they were having on student learning, and/or their influence on the learning culture of the institution. Of course, they did not start out that way. In their respective emergences, they formed organically and tentatively, forging their paths and collective identities over time. Select members of these learning communities were invited to share their respective experiences of a learning community (LC), how they had made meaning of their experiences in it, and how their participation in the LC had informed their professional practice.

\section{Methodology}

This study used an interpretive inquiry methodology. "In some scholarly communities, interpretive approaches have become explicitly associated with a postmodernist perspective" (Thorne, 2016, p. 223). This study asserted the subjectivity of the participants' accounts and of the researcher's interpretations. As a methodology, interpretive inquiry emphasizes the situated individual, uses relatively small sample sizes, and requires that the particular meanings reported by participants be 
set within their contexts (Cohen, Manion, \& Morrison, 2011). Findings are not meant to be generalized but may offer insights that are relevant in other contexts (Butler-Kisber, 2010). These methodological qualities were upheld in this study.

\section{Research Ethics}

This study was reviewed and approved by the research ethics boards at my parent institution and at the college that served as the site for this study. Consent forms were administered and signed by informed and voluntary participants prior to data collection. Subsequently, a transparent, communicative practice (in conversation and in writing) for ensuring ongoing consent was used throughout this study. With each step in the process, participants were informed of their rights to withdraw and of the process for withdrawal of participation. This study received no funding.

\section{Methods of Inquiry}

This study was conducted at a large, urban, publicly-funded college in Canada. A purposive sample of colleagues who had recently participated in an LC was selected. Ten research participants represented five learning communities and four employment classifications: faculty members, support staff, educational developers, and administrators. In order to protect individual and institutional identity in this study, the learning communities were given pseudonyms, namely: (a) Sciences, Arts, \& Culture Collaborating (SACC); (b), Faculty Writing Community (FWC); (c) Indigenizing Education Community (IEC); (d) Integrating Pedagogy and Classroom Design (IPaCD); and (e) Universal Design for Learning Community (UDLC). Similarly, each participant was assigned a code (e.g., A1 represented Administrator 1).

As seen in Figure 1, in this interpretive inquiry process, data was collected through individual inquiry conversations (semi-structured interviews) and research memos in order to develop narrative vignettes representing the participants' respective experiences of an LC. A set of guiding questions was developed for the inquiry conversations, which were audio-recorded and transcribed. Transcripts were stripped of the researcher's voice, sub-headings were added, and acronyms were expanded. These revised transcripts were sent to their respective research participant for member checking (Carlson, 2010).

The participant-approved texts were reviewed, annotated, and coded for units of meaning, identified as themes. A total of 27 themes were grouped into five categories: (a) the nature of an LC; (b) LC motivations and goals; (c) participant motivations for joining an LC; (d) unintended outcomes; and (e) constraints and opportunities. The themes were repeated across many transcripts, demonstrating saturation in the data (Beitin, 2012). Using the language of the research participants, and referring to the research memos, the author crafted narrative vignettes for each theme. The narrative vignettes were then distilled into statements of phenomena, which became the thematic findings of the study. 


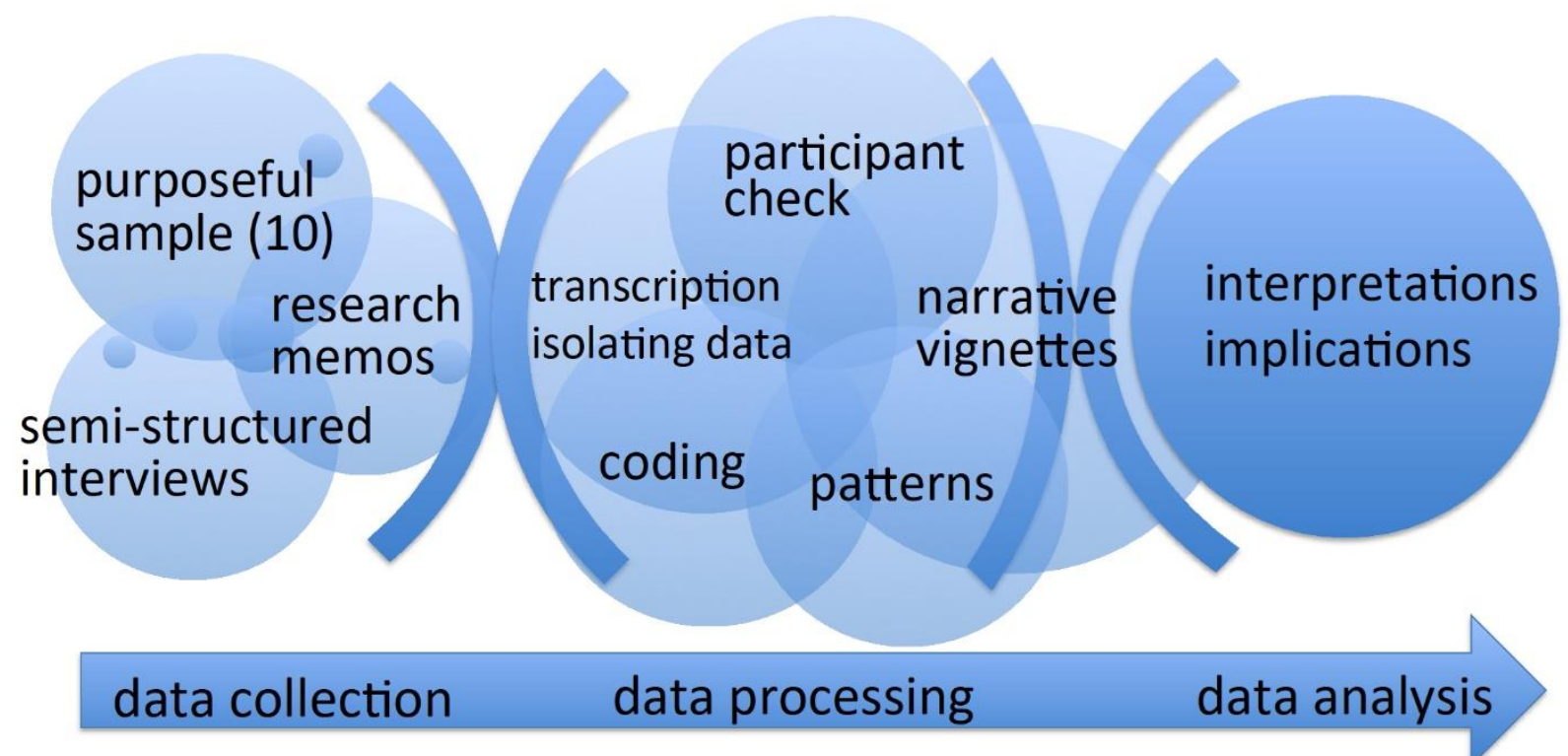

Figure 1: The interpretive inquiry process of data collection, processing, and analysis methods used in the study.

\section{Thematic Findings}

In this section, a selection of the thematic findings is presented, with some accompanying narrative vignettes, in order to draw a portrait of the LCs in this study. This portrait will be distilled further in subsequent sections in which the major findings, the author's interpretations, and the policy and practice implications arising from these findings are discussed.

The thematic findings, written in the author's own words and based on the narrative vignettes, address succinctly the overarching research question posed in this study: What does it mean for faculty, educational developers, support staff, and administrators to participate in a learning community at a college in Canada? Concurrently, the narrative vignettes respond to the research question in more detail and in the words of the research participants. The thematic findings are organized using the 27 themes that emerged from the data, grouped into five categories (for a comprehensive list of these five categories and 27 themes, see Appendix A.) The selection of thematic findings statements and narrative vignettes that follows relate specifically to the context of the Canadian college at the centre of this inquiry. Although the thematic findings statements are written in terms of learning communities, they must not be read as generalizations about all learning communities.

\section{Category 1: The Nature of a Learning Community}

Collaboration and co-design. Learning community members work together, and in so doing create new knowledge that could not have been created by any one individual member on their own. 
Degrees of participation. Varying degrees of participation are critical to sustaining a learning community, as participants in the core, periphery, and penumbra help the learning community to achieve its many goals (see Figure 2).

Peer mentoring. Learning community members learn from each other and support one another in mutual, give-and-take relationships.

Interdisciplinarity. The interdisciplinarity of learning communities responds to the complexities of contemporary societal challenges. Effective interdisciplinary learning communities need one or more translators to draw connections between disciplines, as well as the willingness of all participants to learn to think extra-disciplinarily 7 - outside the norms and paradigms of their own fields of expertise.

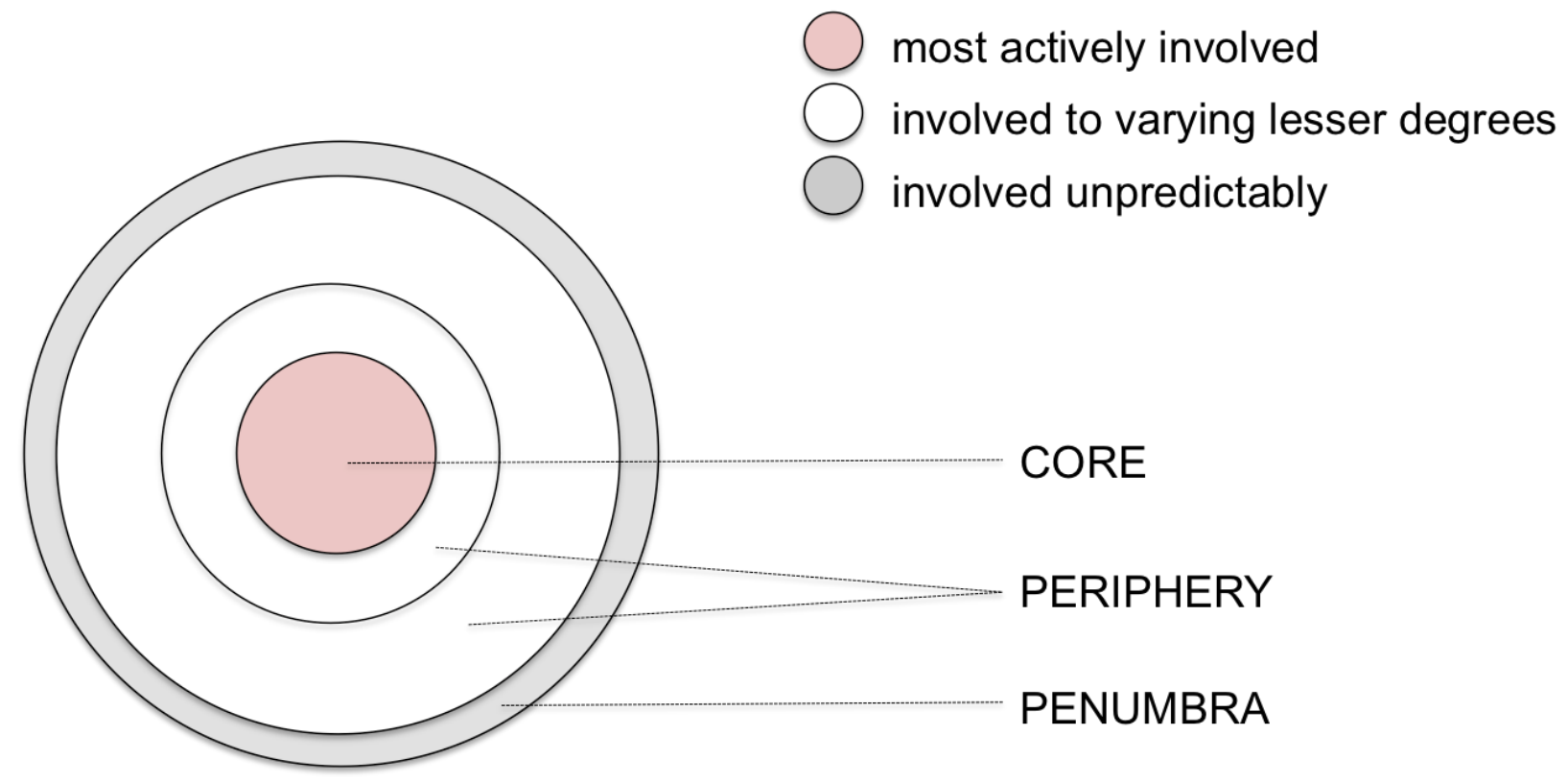

Figure 2. Degrees of participation in an LC with a large, diverse membership.

Productive and goal-oriented. In their early stages of development, learning communities are product- and goal-oriented because members are looking for practical results and may feel they need to prove themselves worthy recipients of support and funding. More established learning communities that have made significant contributions and earned a level of legitimacy or recognition tend to shift to a more process-oriented approach. These phenomena are not seen in opposition, but some learning communities tend more towards productivity and others tend towards a process-orientation.

Shared values. Learning communities allow shared values to emerge among their participants. Once normative, shared values are identifying features of a learning community. Without being directive or prescriptive, the shared values signal to new members what the learning 
community cares about and how it functions. The finest of their collective work comes from a learning community that shares foundational values.

Research or evidence-based. Learning communities are sites of inquiry where researchers and practitioners learn from one another to improve practice and to ground research in a particular context.

Organic emergent process. The establishment of learning communities is hard to engineer or direct. Successful learning communities recognize a gap and respond to it at ame when the broader community is ready for that kind of change. Learning communities bring together a core group of people who create a safe space for exploration and peer-to-peer learning. They use nonlinear, organic processes to emerge as a cohesive community.

\begin{abstract}
Narrative Vignette 1
We know that successful learning communities have something to do with recognizing gaps and harnessing needed expertise to respond to the gaps. It's also about finding the right time when the broader community is ready or open to potential change. It involves a core group of people, who believe in the goals and intentions of the emergent learning community. And there needs to be a safe space, that is not overly structured, to allow for creative ideas to surface, for people to follow a tangent and see where it leads, and for people to be influenced by each other. The emergent nature of successful learning communities means their members have to be able to live with ambiguity and uncertainty, at least some of the time. (Educational Developer and Faculty Member)
\end{abstract}

Sub-culture or microculture. Learning communities are a point of connection for colleagues within a large institution. Connections formed in learning communities foster a greater sense of connection to and pride in the institution. Over time, learning communities within a large institution become microcultures (Mårtensson, Roxå, and Stensaker, 2014; Roxå and Mårtensson, 2015). Several learning communities within a large institution become a network of microcultures that influences the operational culture and the culture of innovation within the institution (Roxå and Mårtensson, 2009) and forges a path for new learning communities and microcultures to develop.

\title{
Narrative Vignette 2
}

We always need to consider the system that is creating the right conditions - multiple parallel factors, such as the philosophical and financial support of the senior leadership, and simultaneously the interest and willingness of colleagues to inquire together, - for the success of our learning communities. Without any of these right elements within the system, we may not get the same kind of result. If our system was void of other learning communities that had their own nexuses, we probably wouldn't have the kind of impact that each community has on its own, or now can have. Our communities are drawing on microcultures of people who are willing to engage in something that is bigger than themselves. If there were just one learning community in the institution, it would not constitute a phenomenon, and it would likely have little impact compared to the impact all 
these learning communities are now having on the way we operate and innovate at the college. (Faculty Member)

\title{
Category 2: Learning Community Motivation/Goal
}

Improving practices. Learning communities attract people who are interested in and committed to improving teaching practices, in order to improve student learning.

\begin{abstract}
Narrative Vignette 3
We see that a small, well-developed, engaged community within the college can enrich the college, and create safer, more inclusive, more engaging, effective, or exciting learning experiences for students, which then starts to influence our organizational culture. [...] Small groups of colleagues have found each other around a shared interest, frustration, conundrum, or vision and they've gone about pursuing it together. Along the way, they've needed to do some learning, in order to achieve their goals. (Administrator)
\end{abstract}

\section{Category 3: Participant Motivations for Joining Learning Community}

Belonging, trusted colleagues, group identity. Learning communities create mutually supportive environments in which members share professional highs and lows. Strong collegial connections between learning community members lead to more effective professional learning and development. Learning communities develop a cohesive group identity through common language and group norms that emerge over time. Learning communities are a site for deeper connection and a sense of belonging for professionals within a large educational institution.

\section{Narrative Vignette 4}

My participation in a learning community has really changed how I feel about working at the college. I feel more connected and grounded here. There was a time when I questioned if this college was the right place for me. Now that I'm involved in the learning community, I feel a great sense of pride being a part of this college. I know I'm where I belong. I wear my college sweatshirt with pride and I let my students know that. It's important for all of us to get involved and to feel connected. (Faculty Member)

\section{Category 4: Unintended Outcomes}

Professional development. Although not an initial intention when joining their learning communities, in hindsight, members recognize their learning community experience served as a site for professional growth and development. Learning community participation inspires further professional development pursuits.

New professional identity. Learning community members bring different identities, perspectives, and practices into their learning community, and, in relationship, influence each other. Some develop new professional identities, becoming boundary-crossers.

Gain self-confidence. Support staff report gains in self-confidence as a result of participation in a learning community with faculty members and/or administrators. Learning communities that include faculty, support staff, educational developers, and administrators are 
breaking down the walls between these employment classifications to build authentic collegial relationships across differences in expertise and role.

\begin{abstract}
Narrative Vignette 5
I used to find it a little intimidating talking to the Academic Dean or a Professor. That always made me nervous because my level of education is not what theirs is. I've always shied away from formal discussions with people in those positions. As we all got to know each other in the learning community, I came to see that we are just people working on a project together. I feel genuinely respected by the faculty leaders. I would have been much more uncomfortable speaking up earlier on; I think I've benefited from participating in the learning community meetings and being encouraged to contribute my ideas. The learning community has definitely helped me develop my self-confidence. It's an important aspect of the learning community because we're breaking down the walls between us. (Support Staff)
\end{abstract}

\title{
Category 5: Constraints and Opportunities
}

Champions of the work of learning communities. Because the innovative projects of learning communities push the boundaries and norms of the institution, they need senior leaders to champion their work in word and deed, through policy, advocacy, practices, and funding.

\section{Narrative Vignette 6 \\ For learning communities to succeed, they need to be initiated from the bottom, they have to have financial support from the top, and also a clear statement from senior management saying they believe learning communities are important, and then, eventually, the influence of the learning communities will move to the middle ranks. It's got to be both bottom-up and top-down. (Faculty Member and Educational Developer)}

Financial support for learning communities. Learning communities are functioning on year-to-year funding from a variety of sources including faculty release time from the college, student success project funding, research grant funds, and project funds from external sources. To be able to implement multi-year and increasingly complex programs, learning communities need sustained operational funding.

Connect learning communities to strategic plan. To secure sustained operational funding, learning communities are working to include the goals and vision of their projects in the next iteration of the institutional strategic plan.

\section{Discussion of Major Findings}

The learning communities in this study emerged as inclusive gatherings of colleagues from across employment classifications and roles. These diverse colleagues with shared curiosities initiated the learning communities, which served as sites for professional development for faculty, support staff, educational developers, and administrators. The data in this interpretive inquiry showed that 
once a critical mass of learning communities was established, they organically formed what some research participants - and Roxä \& Märtensson (2015) — refer to as microcultures within the institution. According to participants in this study, these microcultures then influenced educational and organizational policies and practices. The diverse experiences shared in the inquiry conversations of this study led the researcher to understand this collection or network of learning communities as a complex rhizomatic cluster of connected, non-hierarchical roots and stems (Lather, 1993) that sprouted throughout the college, transforming the institutional culture from a primary focus on credential-granting toward a learning organization (Cox, 2001; Senge, 2006). This study found that the rhizome of learning communities (a) supported faculty and professional development, (b) promoted educational innovations, and (c) effected organizational change.

Faculty and professional development. Although it was not their main goal, high quality professional learning was achieved when colleagues in the learning communities were wrapped up in a complex project that required they learn or build new knowledge together. This LC model thus resulted in faculty and professional development as a by-product of passionate, project-based, peer engagement.

\begin{abstract}
Narrative Vignette 7
Sometimes in the learning community meetings we would engage in pretty vigorous debates, from very different disciplinary perspectives. It took some thinking and rethinking, but eventually I started to see that my own perspective was limited; then I found I was opening myself to a broader view of our role as educators. It helped that when we got into these oppositional discussions we found ways of laughing at our own narrow thinking. (Educational Developer)
\end{abstract}

Recognizing the diverse faculty development needs within the academy, the results of this study have reinforced the importance of supporting faculty-driven and staff-driven learning communities as significant sites for professional learning across roles, disciplines, and departments. Faculty development units may wish to explore how they can participate in and support the emergence of learning communities within their institutions. While faculty learning communities, which are exclusive to faculty members, are a fruitful format for faculty development (Tovar, Jukier, Ferris, \& Cardoso, 2015; Cox, 2004), engaging in and supporting the emergence of professional learning communities opens opportunities for educational developers and faculty development service units to participate in cross-institutional, integrative approaches to faculty development.

Educational innovation. Learning communities in this study were powerful sites for pushing the college in new educational directions, influencing decisions about the allocation of special project resources and faculty release time funds, and gradually shifting the college culture. The findings demonstrated that once educators are informed and knowledgeable about scholarly teaching and high impact pedagogical practices, they feel morally and socially compelled to implement these practices in support of student learning. 


\section{Narrative Vignette 8}

It wasn't as if everyone was starting from zero. One of the things we learned in the community is that we were already practising some of these scholarly teaching approaches without realizing it. By exploring these pedagogies in the learning community, we were deepening our existing practices, acquiring the language to identify what we were doing, and gaining understanding about the benefits of these approaches for student learning. (Faculty Member)

\section{Narrative Vignette 9}

College should not just be about passing students through courses and issuing diplomas. Both students and faculty in our learning community are pushing the learning boundaries; they're not stagnant at all. They're all thinking and learning all the time. I understand where the attitude comes from, when people treat us like a whimsical pet project, especially when resources are tight. People don't want money to be wasted. But we see this as money being invested into transforming education. And we're in it for the long haul. (Support Staff and Faculty Member)

Based on findings from this study, participation in an emergent professional learning community (PLC) is an effective way for colleagues to develop proficiency and expertise in scholarly teaching and high impact pedagogies. Emergent PLCs are indeed sites for educational innovation; that is, emergent PLCs enable the development of new, locally-relevant, scholarly teaching practices in support of improved student learning experiences. Institutions of higher education can reasonably expect transformational results from investing in and supporting emergent PLCs as one avenue towards educational innovation. Benefits beyond educational innovation, such as cross-institutional collaboration, increased employee sense of belonging, and increased pride in the institution can also be expected.

\section{Operational Change.}

\section{Narrative Vignette 10}

I think the college is being challenged to see what kind of institutional change is possible.

I think the inspiration for that discussion to even take place is coming from all the learning communities. We've reached a critical mass of learning communities at the college that are now speaking loudly enough that the college is noticing what a positive impact learning communities are having on student learning. Our learning communities are gradually influencing a shift in the institution and its culture. (Faculty Member)

\section{Narrative Vignette 11}

It's only recently, looking at the network of learning communities that has emerged at the college, that we are starting to make sense of it all by calling each group a learning community. Previously, we did not have the kind of paradigmatic structure of the learning communities to say, "Oh, that's how we do things." We started it on a small scale in many different places, throughout the whole institution. When we look back now, we see at a 
certain point, there were enough initiatives organizing themselves either consciously or unconsciously as learning communities, that they shifted the culture of the institution. Now we're thinking about innovative initiatives within the framework of learning communities. (Administrator and Faculty Member)

Through the relationships of trust and the significant conversations (see Narrative Vignettes 10 and 11; Roxå and Mårtensson, 2009) that occurred in the emergent PLCs in this study, the educational focus, organizational structures, and culture of the college started to shift. When they saw the beneficial effects that learning communities were having at the college in terms of faculty and professional development and educational innovations in support of improved student learning, senior administrators were inspired to consider re-organizing the college using a learning communities model. However, this initiative raised a conundrum: How can the college institutionalize learning communities in order to better support and sustain their functioning without compromising the strength of the grassroots, self-organizing nature of learning communities?

For learning communities to emerge and thrive, support from senior administrators is needed - most especially support for implementing relevant college-wide organizational changes. The most important changes needed are increased flexibility and responsiveness from operational systems (e.g., physical space), scheduling, information technology, hiring policies, and funding cycles. To support the emergence of PLCs, coordination and alignment of service units with educational (pedagogical) innovation, long-term, sustained financial support, and strategic plans and policies that recognize and institutionalize emergent PLCs are critical organizational changes. Flexible, responsive organizational systems will facilitate the development and continuing success of learning communities.

\section{Conclusion}

Learning communities in this study served as sites for professional development, formed microcultures within the institution, and through a rhizomatic cluster of non-hierarchical microcultures influenced improvements to educational and organizational policies and practices. As Cox (2017) reports on the organizational and cultural change agents that emerge from faculty learning communities, in this interpretive inquiry the rhizome of learning communities transformed the institutional culture from one focused primarily on credential-granting toward a genuine learning organization.

Integration of educational development practices within faculty- and staff-initiated professional learning communities significantly benefits the institution by effectively responding to the professional development needs of all actors. This cross-institutional, integrative approach, using a project-based emergent professional learning communities model, opens new pathways for thinking about and designing faculty development programming. If faculty development aims to support and celebrate a culture of scholarly teaching and learning across the institution, perhaps 
the one-time teaching strategies workshop and the singular one-on-one consultation approaches to faculty development are insufficient.

Through this study, I have been compelled to reflect on the influence that a groundswell of emergent PLCs and their corresponding microcultures can have within an institution. I am drawn towards faculty development practice that espouses an integrative philosophy. This study has revealed and reinforced that when colleagues who share a scholarly and/or practitioner curiosity or challenge come together across roles, disciplines, and divisions, the quality of professional peerto-peer learning that occurs has profound and sustained effects on individual professional practices (Roxå and Mårtensson, 2009). When several of these groups of colleagues emerge within a postsecondary institution, they have the potential and power to transform the institution's professional development, educational, and organizational cultures.

\section{References}

Beach, A. L., Sorcinelli, M. D., Austin, A. E., \& Rivard, J. K. (2016). Faculty development in the age of evidence: Current practices, future imperatives. Sterling, VA: Stylus.

Beitin, B. K. (2012). Interview and sampling: How many and whom? In J. F. Gubrium, J. A. Holstein, A. B. Marvasti, \& K. D. McKinney (Eds.), The SAGE handbook of interview research: The complexity of the craft (2nd ed.), (pp. 243-252). Thousand Oaks, CA: SAGE.

Brownell, J. E., \& Swaner, L. E. (2009). Five high-impact practices: Research on learning outcomes, completion, and quality. Washington, DC: Association of American Colleges and Universities.

Butler-Kisber, L. (2010). Qualitative inquiry: Thematic, narrative, and arts-informed perspectives. Thousand Oaks, CA: SAGE.

Carlson, J. A. (2010). Avoiding traps in member checking. The Qualitative Report, 15(5),1102-1113.

Cohen, L., Manion, L., \& Morrison, K. (2011). Research methods in education (7th ed.). New York, NY: Routledge.

Condon, W., Iverson, E. R., Manduca, C. A., Rutz, C., \& Willett, G. (2016). Faculty development and student learning: Assessing the connections. Bloomington, IN; Indiana University Press.

Cox, M. D. (2017). Faculty learning communities: Change agents for transforming institutions into learning organizations. To Improve the Academy, 19(1), 69-93.

Cox, M. D. (2004). Introduction to faculty learning communities. New Directions for Teaching and Learning: Building Faculty Learning Communities, 97(2), 5-23.

Gabelnick, F., MacGregor, J., Matthews, R. S., \& Smith, B. L. (1990). Learning community models. New Directions for Teaching and Learning, 41, 19-37.

Garrison, D. R., \& Anderson, T. E. (2003). Learning in the 21st century: A framework for research and practice. London, UK: Routledge.

Goodsell Love, A. (2012). The growth and current state of learning communities in higher education. New Directions for Teaching and Learning, 132, 5-18.

Heinrich, E. (2014). Towards using relevant collegial contexts for academic development. Active Learning in Higher Education, 15(3), 215-230.

Kuh, G. D. (2009). High-impact educational practices: What they are, who has access to them, and why they matter. Washington, DC: Association of American Colleges and Universities.

Lather, P. (1993). Fertile obsession: Validity after poststructuralism. The Sociological Quarterly, 34(4), 673-693.

Lenning, O. T., \& Ebbers, L. H. (1999). The powerful potential of learning communities: Improving education for the future. Washington, DC: The George Washington University. 
Macpherson, A. (2007). Faculty learning communities: The heart of the transformative learning organization. Transformative Dialogues: Teaching \& Learning Journal, 1(2), 1-16.

Mårtensson, K., Roxå, T., \& Stensaker, B. (2014). From quality assurance to quality practice: An investigation of strong microcultures in teaching and learning. Studies in Higher Education, 39(4), 534-545.

Maxwell, J. A. (2005). Qualitative research design: An interactive design (2nd ed.). Thousand Oaks, CA: SAGE.

Meiklejohn, A. (1932). The experimental college. Madison, WI: University of Wisconsin Press.

Mooney, J. A. (2014). Contemplative practice to compassionate learning community: Developing and sustaining the teacher's inner life as a site for faculty development. In L. Thomas (Ed.), Becoming teacher: Sites for teacher development in Canadian Teacher Education (pp. 364-392). Ottawa, ON: Canadian Association for Teacher Education (CATE).

Mooney, J. A. (2015). Emerging faculty learning modalities: Implications for leadership hierarchies in postsecondary education in Canada. In L. Gómez Chova, A. López Martínez, \& I. Candel Torres (Eds.), 8th International Conference on Education, Research, and Innovation (iCERi) Conference Proceedings. Retrieved from https://library.iated.org/view/MOONEY2015EME

Price, D. V. (2005). Learning communities and student success in postsecondary education: A background paper. Retrieved from http://www.mdrc.org/sites/default/files/full 421.pdf

Roxå, T., \& Mårtensson, K. (2009). Significant conversations and significant networks: Exploring the backstage of the teaching arena. Studies in Higher Education. 34(5): 547-559.

Roxå, T., \& Mårtensson, K. (2015). Microcultures and informal learning: A heuristic guiding analysis of conditions for informal learning in local higher education workplaces. International Journal for Academic Development, 20(2), 193-205.

Schroeder, C. M. (2011). Coming in from the margins: Faculty development's emerging organizational development role in institutional change. Sterling, VA: Stylus.

Senge. P. M. (2006). The fifth discipline: The art and practice of the learning organization. New York, NY: Doubleday.

Thorne, S. (2016). Interpretive description: Qualitative research for applied practice (2nd ed.). New York, NY: Routledge.

Tovar, M., Jukier, R., Ferris, J., \& Cardoso, K. (2015). Overcoming pedagogical solitude: The transformative power of discipline-specific faculty learning communities. To Improve the Academy, 34, 319-344.

Wenger, E. (1998). Communities of practice: Learning, meaning, and identity. New York, NY: Cambridge University Press. 


\section{Appendix A: Thematic Findings by Category}

\begin{tabular}{|c|c|}
\hline Category & Theme \\
\hline $\begin{array}{l}\text { 1. The nature of a learning } \\
\text { community }\end{array}$ & $\begin{array}{l}\text { 1. } \quad \text { Collaboration and co-design } \\
\text { 2. Degrees of participation } \\
\text { 3. } \quad \text { Peer mentoring and exchange or give and take } \\
\text { 4. } \quad \text { Diversity of participation } \\
\text { 5. Interdisciplinary } \\
\text { 6. Productive and goal-oriented } \\
\text { 7. } \quad \text { Share similar values } \\
\text { 8. } \quad \text { Research or evidence-based } \\
\text { 9. } \quad \text { Organic emergent process } \\
\text { 10. Self-selected participants } \\
\text { 11. Sub-culture or microculture }\end{array}$ \\
\hline $\begin{array}{l}\text { 2. Learning community motivations } \\
\text { and goals }\end{array}$ & $\begin{array}{l}\text { 12. Improving practices } \\
\text { 13. Improving student experience, complementing } \\
\text { classroom learning, or learning as fun } \\
\text { 14. Create and provide resources or connection to } \\
\text { information and networks } \\
\text { 15. Institutional cultural change } \\
\text { 16. Educational change } \\
\text { 17. Systems change } \\
\text { 18. Phase founding leaders out of key leadership }\end{array}$ \\
\hline $\begin{array}{l}\text { 3. Participant motivations for joining } \\
\text { learning community }\end{array}$ & $\begin{array}{l}\text { 19. Interest in topic or process } \\
\text { 20. Belonging, having trusted colleagues, or sense of } \\
\text { group identity }\end{array}$ \\
\hline 4. Unintended outcomes & $\begin{array}{l}\text { 21. Professional development } \\
\text { 22. New professional identity } \\
\text { 23. Gain self-confidence }\end{array}$ \\
\hline 5. Constraints and opportunities & $\begin{array}{l}\text { 24. Champions of the work of learning communities } \\
\text { 25. Financial support to learning communities } \\
\text { 26. Teachers as independent or autonomous } \\
\text { 27. Connect learning communities to strategic plan }\end{array}$ \\
\hline
\end{tabular}

